Research Paper:

\title{
The Effect of Shift Reporting Training Using the SBAR Crossark Tool on the Performance of Nurses Working in Intensive Care Units
}

\author{
Azade Inanloo ${ }^{1}$, Nooredin Mohammadi ${ }^{1 *}$, Hamid Haghani ${ }^{2}$
}

1. Department of Critical Care Nursing, Faculty of Nursing and Midwifery, Iran University of Medical Sciences, Tehran, Iran

2. Department of Biostatistics, School of Public Health, Iran University of Medical Sciences, Tehran, Iran.

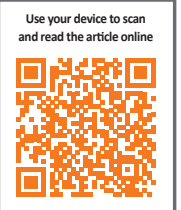

citrat On: Inanloo, A., Mohammadi, N. \& Haghani, H. 2017. The Effect of Shift Reporting Training Using the SBAR Tool on the Performance of Nurses Working in Intensive Care Units. Journal of Client-Centered Nursing Care, 3(1), pp. 51-56. https:// doi.org/10.32598/jccnc.3.1.51

https://doi.org/10.32598/jecnc.3.1.51

Article info:

Received: 01 Oct. 2016

Accepted: 31 Dec. 2016

Keywords:

Work shift delivery report, Nurses, Intensive care unit, SBAR tool

\begin{abstract}
A B S T RA C T
Background: Shift report in nursing profession comprises the collection of information, assessment of nursing cares provided to hospitalized patients, providing an opportunity to get acquainted with patients, and being aware of their caring process. This study aimed to investigate the effect of educating nurses in intensive care units on the reporting of work shift using the SBAR tool.

Methods: The present study is quasi-experimental and interventional. It was conducted with pre/ post training and one-group design. The study was an observational study done by the researcher using a checklist based on SBAR tool. The samples were recruited by census sampling method in the intensive care unit of Hazrat Rasool Hospital, affiliated to Iran University of Medical Sciences. Work shift delivery report was observed using the 18-item SBAR checklist by the researcher once before training reporting (3 work shift delivery reports from each nurse) using the SBAR tool and once after training ( 3 work shift delivery reports from each nurse). In training sessions, reporting method was taught to nurses in the unit based on SBAR tool. After one month of training, nurses' performance in reporting delivery of work shift was evaluated in accordance with the above tool. The collected data were analyzed using SPSS V. 20.
\end{abstract}

Results: Comparison of the performance of nurses in intensive care units before and after work shift delivery report training using the SBAR tool showed a significant statistical difference between the performance scores in all areas before and after the intervention and the scores increased after intervention.

Conclusion: Using the shift work reporting method had a significant effect among the study participants using SBAR tool and improved their performance with regard to work shift delivery report.

\section{* Corresponding Author:}




\section{Background}

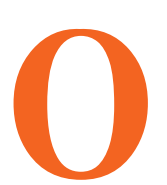

ne of the major responsibilities of nursing profession is how to communicate, report, take report, and record information (Salimi, Rahimi \& Bayazidi 2013). Nursing report is the official exchange of information between nurses in written or oral form at the end of each shift. Besides recording the written report of nurses, oral report is a communication method which its purpose is to transfer essential and key information about patients' medical care (Sabet Sarvestani, Moatari, \& Yekta Talab, 2014). As mentioned, one of the practical reports of nurses is work shift delivery report when the responsible nurse for caring the patient provides the other nurses with a summary of patient's activities and condition at the time of leaving the unit to rest or deliver his or her shift. Work shift delivery report is one of the most common and prevalent methods of reporting to health care team members (Flemming \& Hübner 2013).

The purpose of the work shift delivery report is data collection, evaluation of nursing care delivered to patients, and providing an opportunity to get acquainted with patients. Work shift delivery report should be provided quickly and efficiently and explain well the health status of patients for the next shift staff (Griffin 2010; Shahffi savari \& Peyravi 2009). Providing proper and adequate information during the work shift delivery report is also very effective in improving patient's safety. Carrying out work-shift delivery report of nurses at the bedside also increases patients' satisfaction (Laws \& Amato 2010).

Other benefits of work shift delivery report at the bedside are informing the patient about his or her caring process, upcoming caring plans; reducing patient's anxiety; eliminating the feeling of loneliness and helplessness; increasing nurse's accountability; improving teamwork; and ultimately reducing the incidence of communication errors during work shift delivery report (Schmit 2013). In 2006, Joint Accreditation Committee was formed with the aim of improving patient's safety and communicating properly and effectively at the time of work shift delivery report, and in particular standardizing and applying standard reporting methods (Halm 2013). This committee blamed incomplete and inefficient reports among health care teams as the cause of two thirds of unwanted side effects (Wheeler 2014). In 2011, the World Health Organization emphasized the necessity of comprehensive training of health care team concerning elimination of unwanted harms for patients (Whittingham \& Oldroyd 2014).
In 2011, Institute for Health Promotion announced that SBAR is an easy and efficient tool for using in the work shift delivery report (Randmaa et al. 2014; Lancaster, Westphal \& Jambunathan 2015). SBAR tool can also help improve the team spirit of nurses. This tool contains standard questions divided into four sections and are used to ensure the nurses about sharing the patient's information briefly and concisely (Khodabakhshian \& Khachian 2014). This tool also encourages the nurses to provide effective and accurate reports and to share organized information along with details without mentioning unnecessary information (Whittingham \& Oldroyd 2014).

In our country, work shift delivery report is performed orally and using the nursing kardex and memories of the nurse responsible for the patient's care and without following a uniform and standard instruction (Etezadi et al. 2012). Nursing care is very complex and vital in Intensive Care Units (ICUs) and communicating information using common methods is very challenging and difficult. Unfortunately, nurses do not follow a systematic and integrated approach for their reports. Accordingly, one of the problems and challenges of work shift reporting is the poor communication of information among the nurses. Taking into account the consequences that weak information transfer brings about concerning clinical consequences for the patients, this study was conducted to investigate the impact of using a standardized method called SBAR on work shift delivery report in ICUs hoping to take an effective step in solving existing problems in the field of reporting during the work-shift delivery of nurses in ICUs.

\section{Materials \& Methods}

\section{Study design and participants}

This research is quasi-experimental with one group study where we will not be able to assign subjects randomly to the intervention and control groups. Since matching the conditions is impossible, all nurse were investigated in two stages, once before the intervention as the control group and then after the intervention as the intervention group. The research population in this study comprised all nurses working in ICUs of Hazrat Rasool Hospital affiliated to Iran University of Medical Sciences who had bachelor's degree and higher and at least 3 months of work experience in the ICU. Sampling was done by census method.

\section{Data collection}

The SBAR tool was used for collecting data. This tool is an 18 -item checklist which assigned 0 or 1 score to 
each item. So the minimum score on this tool is 0 and maximum score is 18 . This checklist has been compiled in four areas. The first part contains the patient's individual information such as name, age, gender, date of admission, the initial cause of hospitalization, patient's physician, and current patient's condition (state of consciousness, motor status).

The second part involves patient's medical records before admitting to hospital. The third part contains vital signs, pain status, airway status and respiratory pattern of the patient, hemodynamic status, patient's skin condition, patient's received intravenous fluid, connections to the patient, performed patient's tests, along with reports of patient's abnormal findings. Part four includes report of the nurse caring the patient about the critical and important changes in the patient's condition, medical orders of the doctor, as well as follow-ups to be made by the nurse of the next shift. It is necessary to mention that findings of each item was separately analyzed. The validity of the above checklist was carried out using content validity method and confirmed according to the comments of 10 members of Faculty of Nursing and Midwifery of Iran University of Medical Sciences. Reliability of the checklist estimated to be $0.95(\mathrm{R}=0.95)$ based on correlation coefficient of scores obtained from 10 completed checklists recorded by two observers.

\section{Procedure}

In this study, first, the work shift delivery report was evaluated using the checklist based on the SBAR tool by the researcher ( 3 work shift deliveries of each nurse). Then the reporting method was taught to the nurses of the unit by the researcher during several meetings based on the above checklist. One month after the completion of the work shift delivery instruction, this method was investigated using the SBAR tool (3 work shift delivery report for each nurse).

\section{Data analysis}

Collected data were analyzed using SPSS V. 20 and was described using indicators such as the mean, standard deviation, relative and absolute frequency distribution and median. Collected data were analyzed using one-way ANOVA, paired t test, and Fisher exact test. The significance level was considered less than 0.05 .

\section{Results}

Findings in Table 1 show that most subjects $(83 \%)$ were women and the mean (SD) age range of the subjects was 32.22 (5.16) years. About $65.4 \%$ of the studied subjects were married and $34.6 \%$ were single. Most study participants (88.7\%) had bachelor's de-

Table 1. Demographic characteristics of the study participants

\begin{tabular}{|c|c|c|}
\hline Variables & & No. (\%) \\
\hline \multirow[t]{2}{*}{ Gender } & Male & 9 (17.0) \\
\hline & Female & $44(83.0)$ \\
\hline \multirow[t]{3}{*}{ Age, year } & $<30$ & $17(32.1)$ \\
\hline & $30-40$ & $31(58.5)$ \\
\hline & $>40$ & $5(9.4)$ \\
\hline \multirow[t]{2}{*}{ Marital status } & Married & $34(65.4)$ \\
\hline & Single & $18(34.6)$ \\
\hline \multirow[t]{2}{*}{ Education } & Bachelor's degree & $47(88.7)$ \\
\hline & Master's degree & $6(11.3)$ \\
\hline \multirow[t]{4}{*}{ Work experience, year } & $<5$ & $17(32.1)$ \\
\hline & $5-10$ & $24(45.3)$ \\
\hline & $11-15$ & $8(15.1)$ \\
\hline & $>15$ & $4(7.5)$ \\
\hline \multirow[t]{3}{*}{ Work hours per week } & $<50$ & $1(2.1)$ \\
\hline & $50-60$ & $46(95.8)$ \\
\hline & $>60$ & $1(2.1)$ \\
\hline \multirow[t]{2}{*}{ Work shift } & Morning & $3(5.7)$ \\
\hline & Rotating & $50(94.3)$ \\
\hline
\end{tabular}

Client-Centered Nursing Care 


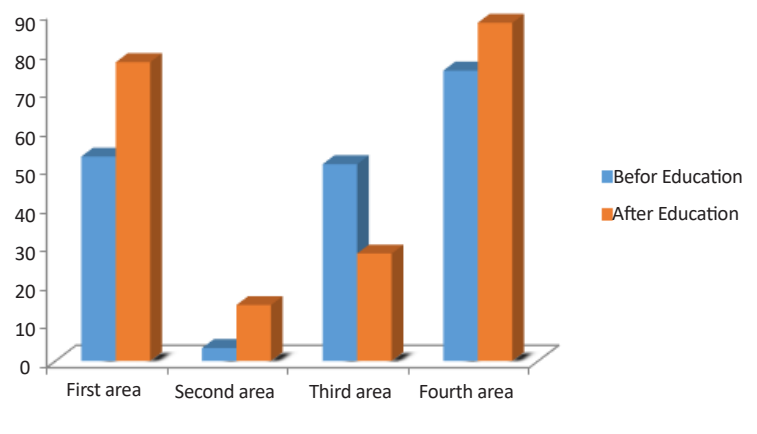

Client-Centered Nursing Car€

Figure 1. Nursing performance areas of special care units before and after training of work shift delivery report

gree. Most participants had a work experience of the 5 - 10 years. About $94.3 \%$ of participants had rotating shifts and only $5.7 \%$ of them had shifts in the morning. Also, $28.3 \%$ were in the ICU surgery and $28.3 \%$ were in the internal medicine ICU. Most of the participants worked 50 to 60 hours a week (95.8\%). Also, all subjects had reported that they did not use a particular method in their work shift delivery report and they did not know the SBAR communication tool.

The findings of Figure 1 show that the mean score in the third area of performance was very low before the training and the highest belonged to the fourth area. While the second and the fourth area had the lowest and the highest mean scores with 14.46 and 87.42 , respectively after the training. The results shown in Figure 2 show that nurses' performance improved after work shift delivery report training using SBAR tool. Paired t test results in Table 2 indicate that the performance score and all its areas showed significant statistical difference before and after the intervention and the score has increased after the intervention in general performance and all areas $(\mathrm{P}<0.001)$.

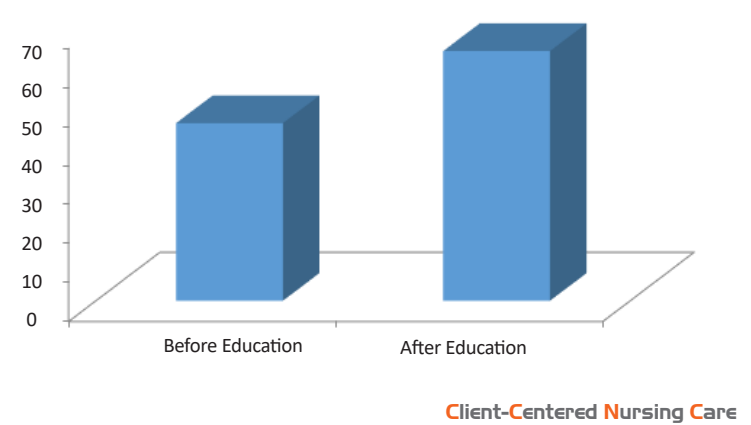

Figure 2. Performance of nurses in intensive care units before and after work shift delivery report training

\section{Discussion}

The current study findings indicate that the mean score of performance was very low in the third area, i.e., monitoring of patient's vital signs and pain, and in general, the patient's clinical condition. However, it has been the highest in the fourth area, i.e., reports of the nurse caring on the patient about critical changes and medical orders of the doctor and subsequently it has improved the performance. Also the results obtained from determining the performance of nurses in the ICU after teaching work shift delivery reporting using the SBAR tool indicate that second and fourth areas had the lowest and highest mean scores after training.

Therefore, nurses participating in this study showed the best performance in the fourth area, i.e., the report by the nurse caring on the patient, after training. However, performance in the second area, that is, the medical records of the patient before the admission was lower than other areas. Comparison of nurses' performance in the ICU before and after work shift delivery report training using the SBAR tool showed that performance and all its areas had significant statistical difference before and after intervention and increased after intervention.

Table 2. Performance areas of nurses in intensive care units before and after the work shift delivery report

\begin{tabular}{|c|c|c|c|}
\hline \multirow{2}{*}{ Performance Areas } & Before the Intervention & After the Intervention & \multirow{2}{*}{ Paired T-Test } \\
\hline & Mean (SD) & Mean (SD) & \\
\hline First area & $52.83(11.43)$ & $77.24(11.56)$ & $t=13.64, d f=52, P=0.0001$ \\
\hline Second area & $3.35(7.08)$ & $14.46(17.78)$ & $t=5.35, d f=52, P=0.0012$ \\
\hline Third area & $50.86(12.66)$ & $77.27(13.19)$ & $t=4.54, d f=52, P=0.0005$ \\
\hline Total & $45.52(7.31)$ & $63.99(9.75)$ & $t=14.26, d f=52, P=0.0011$ \\
\hline
\end{tabular}


Based on the obtained results, this study show that using the shift work reporting method among the participating nurses employing the SBAR tool played a significant role in improving the performance of nurses. The present study results were similar to a study that evaluated the impact of implementing a codified guide on work shift delivery report on nurses' safe performance in the cardiorespiratory ward (Etezadi et al. 2012). This similarity was in terms of the effectiveness of work shift delivery report training on the performance of nurses. With regard to the evaluation of SBAR method, De Meester et al. (2013) study showed that using SBAR tool considerably reduced the rate and report of incidents caused by inappropriate connection and weak relationship of physician and nurses from $31 \%$ to $11 \%$ after the intervention which like our study, referred to the effectiveness of the SBAR method.

Other studies, including Sears et al. (2014), Randmaa et al. (2014) and Cornell et al. (2014) showed that using SBAR communication tool has been very effective in improving the level of patient's safety, reducing the time spent on shift delivery of nurses, and improving nurses' professional relationships. A study on nurses and hospital doctors in the state of Arizona showed a significant relationship between using SBAR communication tool and teamwork quality among healthcare and patient safety team (Beckett \& Gayle 2009). Also Jukkala et al. (2012) in examining the impact of using a standard tool in promoting communication between nurses when reporting work shift delivery showed that using the standard tool significantly improved the quality of nurses' communication during work shift delivery.

The results of the present study showed that using the SBAR tool by affecting different areas has been very effective in improving nurses' performance in the work shift delivery report in the ICUs. Therefore, this research is an evidence of the effectiveness of SBAR training program in the development of nurses' capabilities in the field work shift delivery report in hospitals.

\section{Acknowledgments}

The current research has been conducted based on a research project approved by the Ethics Committee (No. IR.IUMS.REC.1394.92114492 dated 26/01/2016) in Faculty of Nursing and Midwifery, Iran University of Medical Sciences. The researchers express their gratitude to counselors and specialists in Hazrat Rasool Health Center affiliated to Iran University of Medical Sciences and all those who contributed to this research.

\section{Conflict of Interest}

The authors declared no conflicts of interest.

\section{Reference}

Beckett, C. D. \& Kipnis, G., 2009. Collaborative communication. Journal For Healthcare Quality, 31(5), pp. 19-28. doi 10.1111/j.1945-1474.2009.00043.x

Cornell, P., et al., 2014. Impact of SBAR on nurse shift reports and staff rounding. Medsurg Nursing, 23(5), pp. 334-43. PMID: 26292447

De Meester, K., et al., 2013. SBAR improves nurse-physician communication and reduces unexpected death: A pre and post intervention study. Resuscitation, 84(9), pp. 1192-6. doi: 10.1016/j.resuscitation.2013.03.016

Etezadi, T., et al., 2012. Nursing handover written guideline implementation: A way to improve safe performance of nurses in intensive care units. Evidence Based Care, 2(2), pp. 7-18. doi: 10.22038/EBCJ.2012.394

Ferris, C., 2013. Implementing bedside shift report. American Nurse Today, 8(3), pp. 47-9.

Flemming, D. \& Hübner, U., 2013. How to improve change of shift handovers and collaborative grounding and what role does the electronic patient record system play? Results of a systematic literature review. International Journal of Medical Informatics, 82(7), pp. 580-92. doi: 10.1016/j.ijmedinf.2013.03.004

Griffin, T., 2010. Bringing change-of-shift report to the bedside. The Journal of Perinatal \& Neonatal Nursing, 24(4), pp. 348-53. doi: $10.1097 / j p n .0 b 013 e 3181 f 8 a 6 c 8$

Halm, M. A., 2013. Nursing handoffs: Ensuring safe passage for patients. American Journal of Critical Care, 22(2), pp. 158-62. doi: $10.4037 /$ ajcc2013454

Jukkala, A. M. et al., 2012. Developing a standardized tool to improve nurse communication during shift report. Journal of Nursing Care Quality, 27(3), pp. 240-6. doi: 10.1097/ ncq.0b013e31824ebbd7

Khodabakhshin, S., \& Khachian, A., 2014. [The clinical guide of fundamentals in nursing (Persian)]. Tehran: Jame'negar.

Lancaster, R. J., Westphal, J. \& Jambunathan, J., 2015. Using SBAR to promote clinical judgment in undergraduate nursing students. Journal of Nursing Education, 54(3), pp. 31-4. doi: 10.3928/01484834-20150218-08

Laws, D. \& Amato, S., 2010. Incorporating bedside reporting into change-of-shift report. Rehabilitation Nursing, 35(2), pp. 70-4. doi: 10.1002/j.2048-7940.2010.tb00034.x

Randmaa, M., et al., 2014. SBAR improves communication and safety climate and decreases incident reports due to communication errors in an anaesthetic clinic: A prospective intervention study. BMJ Open, 4(1), p. 004268. doi: 10.1136/bmjopen-2013-004268 
Sabet Sarvestani, R., Moatari, M. \& Yekta Talab, S., 2014. [Nursing shift report (Persian)]. Tehran: Jame'negar.

Schmit, C., 2013. Emergency department nurses reporting at the bedside to intensive care nurses (Internet), viewed 9 August 2013, http://199.117.41.73/documents/seminars/19_ED_Nurses_ Reporting_at_Bedside_to_ICU.pdf

Sears, K., et al., 2014. The evaluation of a communication tool within an acute healthcare organization. Journal of Hospital Administration, 3(5). doi: 10.5430/jha.v3n5p79

Shahsavari, S., \& Peyravi, H., 2009. Nursing documentation (Persian)]. Tehran: Boshra.

Salimi, S., Rahimi, J. \& Bayazidi, S., 2013. [Nurses' experiences regarding error reporting process: Findings of a qualitative study (Persian)]. Journal of Urmia Nursing And Midwifery Faculty, 11(6), pp. 434-448.

Wheeler, K. K., 2014. Effective hand off communication. OR Nurse, 8(1), pp. 22-6. doi: 10.1097/01.orn.0000438472.00326.1a

Whittingham, K. A. \& Oldroyd, L. E., 2014. Using an SBAR keeping it real! Demonstrating how improving safe care delivery has been incorporated into a top-up degree programme. Nurse Education Today, 34(6), pp. 47-52. doi: 10.1016/j. nedt.2013.11.001 